\title{
The Charles Sturt University Model - Reflections on Fast-track Implementa- tion
}

\section{Prof. Euan Lindsay, Charles Sturt University}

Professor Euan Lindsay is a Mechatronic engineer, a discipline that integrates computers, electronics and physical hardware. Prof Lindsay's PhD investigated whether remote and simulated access alternatives to the traditional in-person laboratory experience could provide the same learning outcomes for students.

Prof Lindsay's work in Remote and Virtual laboratory classes has shown that there are significant differences not only in students' learning outcomes but also in their perceptions of these outcomes, when they are exposed to the different access modes. These differences have powerful implications for the design of remote and virtual laboratory classes in the future, and also provide an opportunity to match alternative access modes to the intended learning outcomes that they enhance.

Prof Lindsay is the Foundation Professor of Engineering at Charles Sturt University. His research interests include engineering education, telecontrol (particularly internet-based telecontrol), artificial neural networks, and rehabilitative technologies for people with sensing impairments.

Prof Lindsay was the 2010 President of the Australasian Association for Engineering Education. He is a Fellow of Engineers Australia, and a Fellow of the UK Higher Education Academy. Prof Lindsay was the recipient of a 2007 Carrick Award for Australian University Teaching. In 2005 he was named as one of the 30 Most Inspirational Young Engineers in Australia.

\section{Dr. James R. Morgan, Charles Sturt University}

Jim Morgan is the father of two daughters and the spouse of an engineer. Before joining Charles Sturt University as Professor of Engineering in 2015, he was at Texas A\&M for 30 years, most recently as an associate professor of civil engineering. Jim has been active in the freshman engineering program at A\&M for nearly 20 years; was an active participant in the NSF Foundation Coalition from 1993 to 2003; also has received funding for his engineering education research from the Department of Education FIPSE program and from the National Science Foundation CCLI program. He is active in the American Society for Engineering Education, is past chair of the Freshman Programs Division, currently serves on the steering committee. In addition to his teaching in engineering, Jim served several years as Co-Director of the Eisenhower Leadership Development Program in the Center for Public Leadership at the George Bush School of Government and Public Service; and also served as director of Aggie STEM with funding from the Texas Education Agency and the Texas Higher Education Coordinating Board. 


\title{
The Charles Sturt University Model - Reflections on Fast-track implementation
}

\begin{abstract}
Charles Sturt University (CSU) has established a new degree in Civil Systems Engineering, with the first intake of students commencing in February 2016. CSU initiated its engineering course as a response to demand from local government and regional industry to address a shortage of engineers in the regions. While the genesis of the program was based in a regional outlook, the mission of CSU Engineering is far more than just providing access for regional students - there was a deliberate mission to anticipate and pre-empt global trends in higher education.

The key aim is to train entrepreneurial engineers in a regional setting. Regional engineering practice requires a number of valuable and transferrable skills - resilience, adaptability, a willingness to accept responsibility early, communicating with non-engineers. These skills are essential for regional practice; however they are also in demand throughout all of industry. As the only Australian engineering program based in a Faculty of Business, we have set ourselves a goal of educating a very different type of engineering graduate, and doing so in a very different learning environment.

The engineering degree program has been developed on a fast-track timeline, with just 503 days from University Executive approval through to the commencement of the first cohort of students. This paper details the specific goals of the program and the non-traditional nature of the curriculum that has been developed to meet them, and discusses the challenges that were overcome to make the program happen within the timeline provided.
\end{abstract}

Introduction

Charles Sturt University (CSU) has established a new degree in Civil Systems Engineering, with the first intake of students commencing in February 2016. CSU has not previously offered degrees in Engineering; this has provided CSU with the opportunity to develop the degree from scratch, providing a "greenfields" site for the program.

CSU initiated its engineering course as a response to demand from local government and regional industry to address a shortage of engineers in the regions. While the genesis of the program was based in a regional outlook, the mission of CSU Engineering is far more than just providing access for regional students - there was a deliberate mission to anticipate and preempt global trends in higher education.

The key aim is to train entrepreneurial engineers in a regional setting. Regional engineering practice requires a number of valuable and transferrable skills - resilience, adaptability, a willingness to accept responsibility early, communicating with non-engineers. These skills are essential for regional practice; however they are also in demand throughout all of industry. As the only Australian engineering program based in a Faculty of Business, we have set ourselves 
a goal of educating a very different type of engineering graduate, and doing so in a very different learning environment.

The engineering degree program completed all of the CSU internal governance processes in 2015, the first cohort of 29 students commenced on February $29^{\text {th }}, 2016$. This paper details the specific goals of the program, the non-traditional nature of the curriculum that has been developed to meet them, and discusses the challenge that were overcome to make the program happen within the timeline provided.

The Goals of the Program

A key feature of the development of the course was a mandate to produce an engineering program that was "orthogonal" to existing Australian engineering degree offerings - it should be a unique offering, rather than simply replicating common practice at the 37 existing schools. After careful consideration of existing engineering programs, we identified five key points of distinction for the program:

Entrepreneurial Graduates. Despite consistent demand from industry for graduates with better business skills, there is no Australian Engineering School that makes this their key focus. CSU Engineering is housed within the Faculty of Business, and one of the research strengths of the Faculty is entrepreneurship. This allows these skills to be made part of the core business of the degree, rather than an add-on elective, or projects serviced by a central university unit.

$4 \times 1$ year work placements. A key driver of our program was to help solve a workforce need in regional Australia. Many engineering organisations are already employing cadet engineers on an ad hoc basis - either employing them part time while they study by distance, or employing them every summer between teaching semesters at an on campus university. This workforce demand allows us the opportunity of embedding our student engineers in industry while they learn, and to provide them with real (rather than realistic or authentic) learning environments. The benefits of co-op programs are widely known; extending from a six-month placement to four years' work experience will only deepen the value of the learning. This also provides an inherent solution to the imminent problem of many engineering students struggling to find adequate workplace experience in order to graduate.

An Innovative curriculum. Building a new program from the ground up allows us to take advantage of the leading edge in educational pedagogy and technology, rather than simply replicating the traditional lecture-tutorial-laboratory paradigm. When academic engineers do meet student engineers in a classroom setting, it will be in a cooperative learning paradigm ${ }^{1}$ much more akin to an engineering workplace than a traditional classroom.

A Diverse cohort. The boutique nature of our program allows us to proactively ensure that the cohort is not homogenous - we are able to ensure that women, minorities, indigenous and regional students are all well represented. Our selection processes are geared towards interviews with potential students, rather than a simple reliance upon university entry scores, with all of their inherent biases. There are significant efforts being made to "move the needle" with regard to representation of minorities in engineering programs; however the single most effective mechanism for having diversity in your intake appears to be to already have diversity in your cohort. Starting from scratch allows us to proactively seek critical mass from the beginning, rather than dooming ourselves to push uphill thereafter. 
A Head start on Chartered status. The additional time offered by a Masters level qualification allows us to achieve more than the Stage One Washington Accord competencies ${ }^{2}$; the embedded work placements will provide accelerated progress towards acquiring competencies of a Chartered Professional Engineer (CPEng) prior to graduation, fast-tracking your path to being recognised as an autonomous professional. A strong engagement with Engineers Australia ensures that we are able to progress our students towards this goal without misrepresenting or misleading people in the process.

The Rapid Timeline

The overall timeline for development and implementation of the program was 503 days, from Senior Executive approval on 14 October 2014, through to the commencement of the first students on 29 February 2016. The keystone of meeting the timeline was "Tangible Curriculum Week" (TCW) in February 2015. TCW was attended by 16 delegates ranging from national and international academic leaders in Civil Engineering Education, industry partners, CSU experts in online learning and development, representatives of the service teaching areas (such as the School of Computing and Mathematics) and even a brief cameo from the Vice Chancellor.

Throughout the week the delegates drew upon their collective wealth of experience and scholarship in engineering education to build a curriculum model that would address the specific mission and goals of CSU Engineering, while maintaining contact with the University's governance and committee structure to ensure that the model was in fact feasible. The Tangible Curriculum Week process has been described in detail elsewhere ${ }^{3}$. The course structure described below, with the Civil Engineering Topic Tree and the Portfolio stream, is largely a consequence of that gathering.

In parallel with the curriculum model, an accelerated faculty recruitment process was conducted. Two Full Professors were appointed by invitation (one has since been confirmed in a competitive recruitment round) and further eight faculty were appointed through a competitive selection round in mid 2015. These faculty include two Lecturers with Engineering Education PhDs, along with three Engineers in Residence who have moved from industry into academia to provide immediately recent industry context and experience to the teaching team. Most of the faculty are junior appointments, which served to mitigate the risks of the short timeline - many were already in the process of exiting previous roles as $\mathrm{PhD}$ students, postdoctoral fellows or research associates, and as such had much shorter notice periods than is customary for more senior academics.

The CSU Curriculum

The course is $5 \frac{1}{2}$ year program, comprising 18 months face to face teaching at the CSU campus and then a sequence of four one-year paid work placements in industry. The program is a combined degree, with graduates awarded both a Bachelor of Technology and a Master of Engineering (Civil Systems). It is important to note that it is an integrated five-year program, and not a 3+2 structure; the award of two degrees is driven not by the course structure, but by the volume of learning requirements of the Australian Qualification Framework ${ }^{4}$. 
The course will cover the main areas of Civil Engineering - Structural, Water, Geotechnical, Roads etc. All graduates will require a baseline exposure to all areas. Our exact specialties will expand as the student pipeline grows and additional faculty come on board.

The curriculum (Figure 1) is designed around a strong portfolio theme, where Student Engineers use examples from their on-campus challenges (years 1\&2) or their workplace experience to demonstrate their achievement of the learning outcomes, rather than completing assignments contrived for an academic environment. Student Engineers will complete two extended projects while in industry - a Cornerstone project in their second placement and a Capstone project in their final year placement.

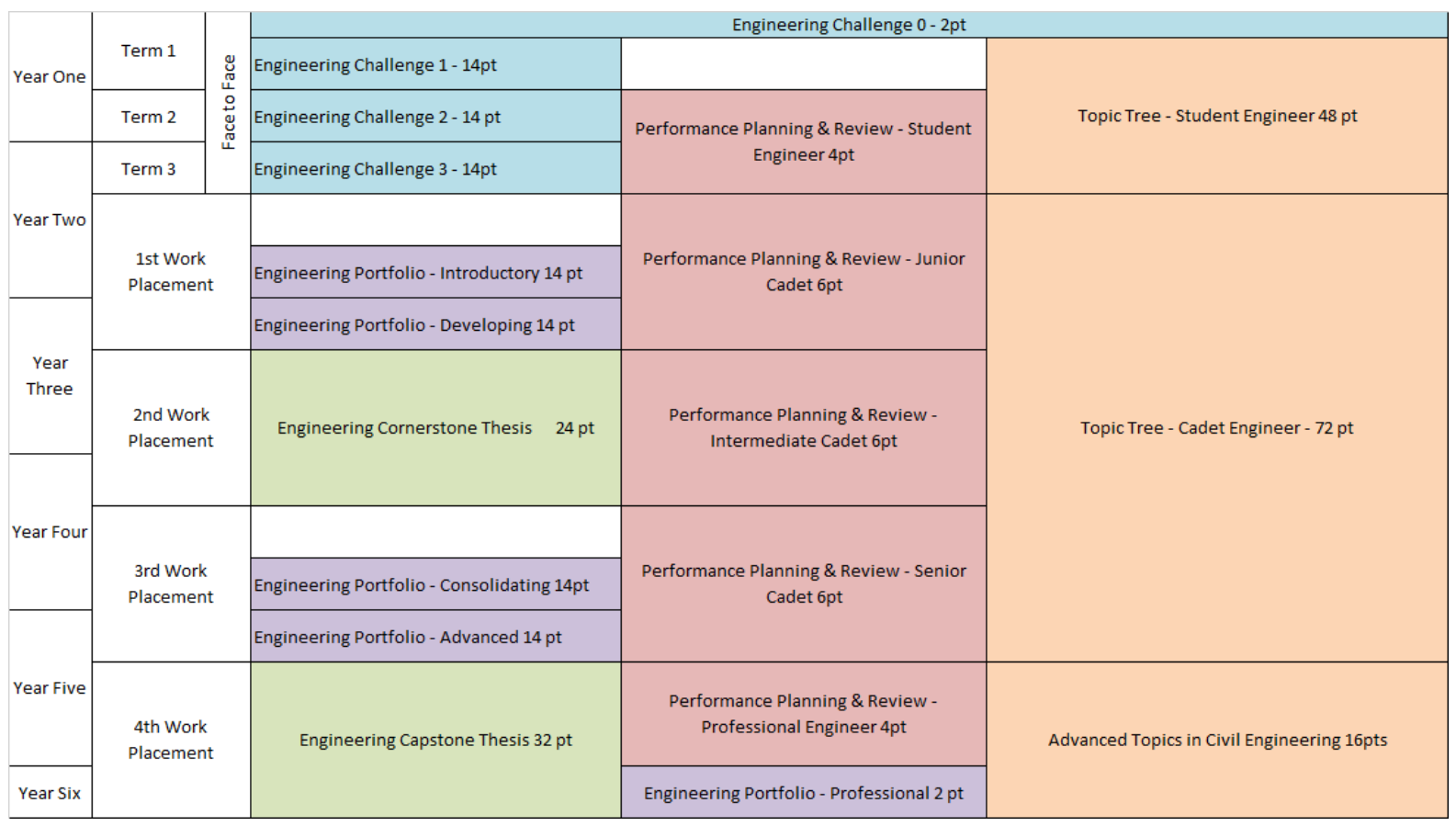

Figure 1: The Curriculum Map

The curriculum eschews the traditional four-subjects-per-term model; the overall program has a total of only 19 subjects for the full 51/2 years. Many of the subjects running over multiple semesters; the longest running subject lasts for three years.

The curriculum is structured with three Pillars: a challenge / workplace / thesis strand; a mastery of topics from the Topic Tree strand; and a Performance Planning \& Review strand. The look and feel of each strand will be similar from year to year; however, the level of knowledge and skill demonstrated by the students in their portfolio is expected to increase each term - achieving Engineers Australia stage one competencies for the Technologist by the end of their second placement, and reaching beyond stage one competencies for a Professional Engineer by the end of the degree.

The challenge / portfolio strand is built around a project-based-learning approach ${ }^{5}$. The curriculum includes realistic challenges during the face-to-face first 18 months, as well as real projects students bring from work placements and theses in the next 48 months. Students will compile a portfolio clearly illustrating the work they have done, the knowledge and skills they have acquired, and a reflective self-assessment of their learning.

The Performance Planning \& Review portion of the curriculum will provide a reality check for students and allow academic staff to help students maintain progress at an appropriate rate, as well as to maintain balance between their efforts related to the project-based-learning and 
mastery-learning strands of the curriculum. These subjects also help the student to develop into a reflective practitioner and from student engineer to professional engineer.

Although we commence with the Student Engineers on campus, the educational philosophy of the course is to take full advantage of the online experience. Where possible the teaching staff will take advantage of online technologies to deliver material, allowing academic staff to utilise our face-to-face time for more educationally valuable interactions with our Student Engineers. This online environment will be scaffolded in the first 18 months on campus, as we form a cohort identity. Then, as students move into industry, their everyday face-to-face support regarding practice will come from the workplace, while the academics continue to provide mentoring on the underpinning theory.

A strong theme of reflective practice runs through the program, with Student Engineers expected (and taught) to manage their own professional development, first in the highly scaffolded CSU Engineering on campus environment, then in the industry work placement environment, and then after graduation as professional engineers. In this way students are active participants in their learning and building these skills to take into their professional lives.

Flexible delivery - the Civil Engineering Topic Tree

The biggest point of difference in the CSU Engineering curriculum is in the Civil Engineering Topic Tree. Traditionally Problem and Project Based Learning curricula embed a PBL subject (sometimes double-sized) amongst a range of standard sized traditional "content" subjects. The CSU Engineering curriculum disaggregates the content of these subjects into multi-semester shell subjects known as the Civil Engineering Topic Tree.

The Topic Tree subjects are essentially shell subjects, comprised of a collection of fine- grained learning topics, each having its own learning objectives and mini-syllabus. Pre-requisite knowledge is mapped to the topic, rather than to a whole subject; this allows a more precise calibration of what is required. Students will be required to plan and monitor their progress through the Tree using a custom-built online interface, identifying what they need to learn and when they need to learn it. Topics will be scaled such that an average student would require an average of three hours to complete the topic.

The Topic Tree is best represented graphically (Figure 2). This small excerpt of the Topic Tree illustrates six topics and the interdependencies between them: Integration along a line, integration along a curve, free body diagrams, shear force diagrams, bending moment diagrams and shear stress in an I-beam, with the arrows showing the pre-requisite links. 


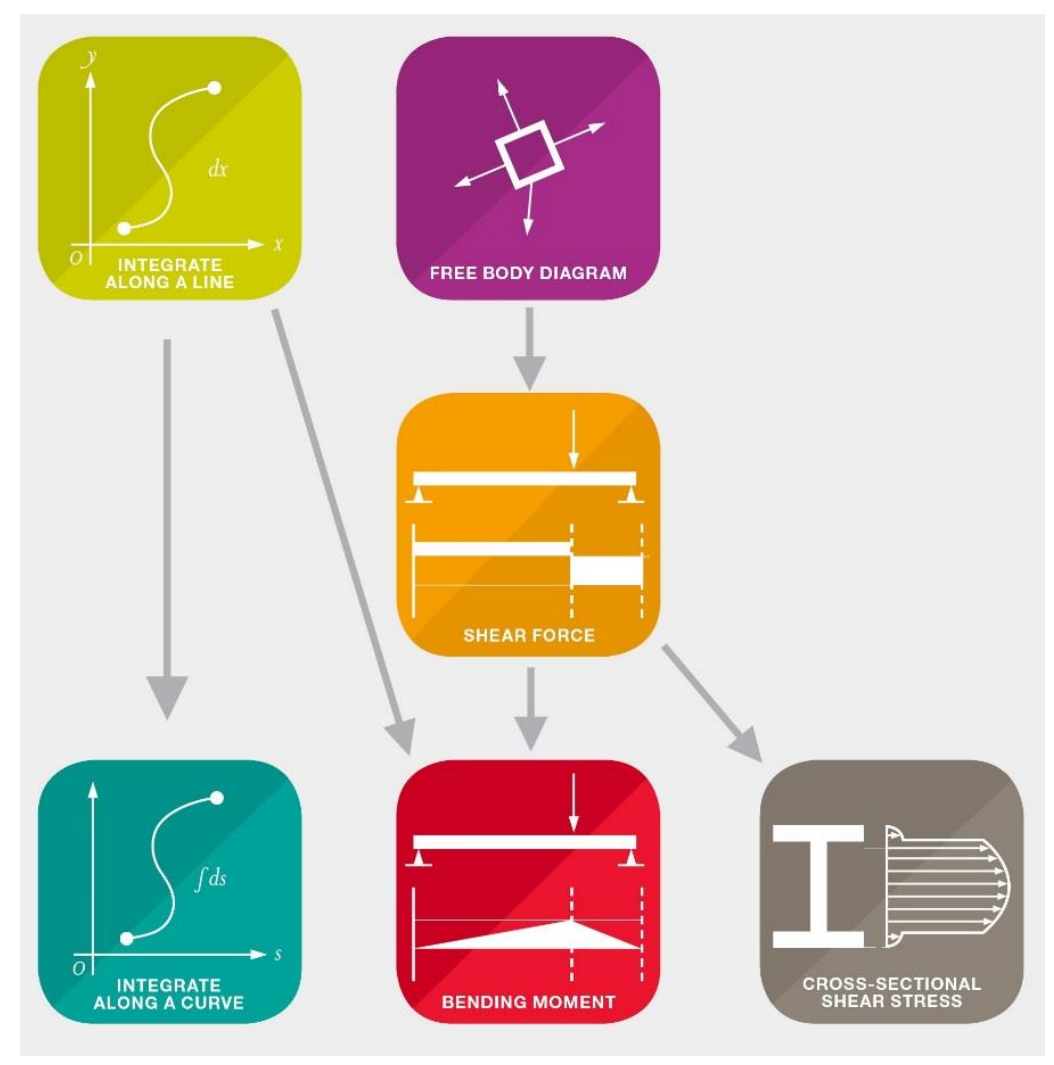

Figure 2: Excerpt from the Civil Engineering Topic Tree

It is this fine granularity that is the strength of the Topic Tree approach. The Free Body Diagram - Shear Force Diagram - Bending Moment Diagram sequence is the traditional core of a first year Statics subject; however the other topics usually reside in other subjects, some in later semesters. This approach allows students to pursue knowledge at the time they require it, rather than learning things that they do not yet need because we have packaged them in the same subject. In particular, the Topic Tree allows students to align their study with the work they are doing while on placement. As they encounter new tasks in the workplace, they are able to delve into the Topic Tree for learning, working with a "just-in-time" approach to learning rather than a "just-in-case".

We anticipate that the overall Topic Tree will contain around 1,000 topics, covering the range of different specialties within Civil Engineering, as well as accounting for different levels of preparation from the commencing students. Presently the Tree has around 700 identified topics.

Core topics within the Tree are allocated to one of three Schedules. Schedule A represents the key skills necessary to function in the workplace as a cadet engineer. Schedule B represents the core knowledge that all Civil Engineers must acquire in their studies. Schedule C represents the specialty-specific knowledge for each discipline, with each student required to complete the version of Schedule C that corresponds to their intended major - Water, Structures or Geotechnical Engineering. In order to pass the respective Topic Tree subjects, student engineers must complete all of the relevant schedules (A for the Student Engineer subject, B and one $\mathrm{C}$ for the Cadet Engineer subject) as well as a sufficient number of topics overall (240 and 600 respectively) to indicate an adequate knowledge base. 
The Topic Tree approach moves the students to a Mastery learning paradigm. Each topic is assessed based on a mastered or not yet basis. This is contrasted with a pass in a traditional subject; meaning that a student has mastered $50 \%$ of the topics in the subject, or is half proficient at each of the topics in the subject. Students progress when they have acquired the knowledge to a required standard. If this occurs quickly, they can advance quickly; if it takes longer, then the student can take the time, rather than missing out.

Where possible (and appropriate), automated assessment and feedback will be used to support the student learning. There are wide ranges of tools that are able to provide students with "nearmiss" feedback in the event that they make common errors.

This approach is most powerful in the learning of topics that are usually implemented through the use of lots of tutorial practice questions, such as finding the maximum stress in a beam. Students can be provided with multiple, personalised, versions of the questions, and then given tailored feedback if they make the errors that have been anticipated by the academics. Once they are able to demonstrate they have mastered the skill, by completing sufficient questions correctly, they can be awarded the topic and then progress - without the need for direct intervention from an academic.

Freeing academics from the repetitive grind of basic marking allows them to instead focus their efforts on more high-value interactions with students ${ }^{6}$ - working with teams ${ }^{7}$, mentoring, role modelling and deeper exploration of content material. Making use of data analytics provided by the interface tools will allow the academics to tailor their face-to-face teaching to respond to the errors most commonly made by the current cohort of students.

Finding Placements

The success of the program is heavily dependent upon finding a pipeline of work placements for the student engineers. Student Engineers use examples from their workplace experience to demonstrate their achievement of the learning outcomes, rather than completing assignments contrived for an academic environment. Placements must consist of engineering work, in an engineering workplace, and under the supervision of an experienced (preferably Chartered) engineer.

CSU is a multi-campus institution, with six campuses spread throughout regional New South Wales, and in most instances CSU is the only university represented in those locations. As a result the university has strong links to the local communities, industries and employers. This has allowed for an early buy-in of Foundation Partners to host our cadets - these are employers who have previously been excluded from engaging more closely with CSU because of our lack of an engineering program, but who are now able to participate.

The faculty cohort includes three Engineers in Residence - practising engineers who have come directly from industry into an academic role, and who have been hired based on their industrial, rather than academic, experience. These faculty are well connected to the various professional and discipline based associations, and these connections have been used to great 
effect. Engineers Australia has regional chapters; there are also societies for Public Works engineering and for Local Government engineers. These have proved very effective in giving the program visibility - in a large part their memberships are the very employers whose workforce difficulties have contributed to the establishment of CSU Engineering.

Scenario Weeks

It is inevitable that not all of the learning outcomes for the Student Engineers will be able to be satisfied on every placement; as a result there is a need for a mechanism for the cadets to "fill in the gaps" in their learning. This mechanism will be the Scenario Week. A Scenario Week is a weeklong residential school, based either at a CSU campus where a particular learning outcome is anchored (e.g. availability of specific equipment), or in a community where a specific project / problem is located.

Scenarios will be selected to provide a wide range of opportunities for engagement with multiple branches of the curriculum. For example, the scenario of designing bike paths for a town provides opportunities across our range of disciplines - pavements for the paths, drainage from the paths, where the paths should go through town, what kind of bridge to use to cross the creek, how to consult with residents; all are options for engagement with the project. At the completion of the week participants need to provide their reports to our partner (and to copy these to their portfolios).

A particular strength of this approach is the opportunity for intergenerational mentoring. Scenario Weeks are open to the whole cohort, allowing for mixing of student engineers at all levels. The ability to lead, mentor and evaluate other engineers is a key skill for the progression of any engineer's career, however it is one that is seldom provided in a traditional degree program due to the homogeneity of most of the teams that a student experiences.

\section{Accreditation}

Accreditation of this program will occur through Engineers Australia (EA). Full accreditation of engineering degrees requires graduates, and as such will not be possible until at least 2021. Provisional accreditation is achievable sooner, however the compressed timeline has meant that this application has been deferred until all the pieces are in place.

Extensive discussions are underway with EA, who have visited CSU to consider the program, and who have concluded that the degree is indeed accreditable. EA are aware of the nontraditional nature of the program, and the full extent of the innovation, and welcome the opportunity to accredit it - once the building, faculty, students and curriculum are all in place. 
The CSU Engineering degree represents a significant deliberate departure from traditional engineering programs. The distinct mission for the program leads to non-traditional goals for the graduates of the program, and the curriculum model draws upon emerging trends in engineering education to meet these goals.

The mandate to develop a qualitatively different engineering degree gave CSU Engineering the opportunity to explore curriculum innovations that are known to work elsewhere, but have only had limited opportunity for application. The strong links to industry also support a mastery learning paradigm - leading to a focus on what the students should learn, and whether they have learned it, rather than a focus on what should be taught in what order and at what time.

The short timeline for implementation originally posed risks for successful implementation, but it also served to remove some of the traditional barriers to program development. The short timelines were more familiar to the industry partners of the program; the continued consistent sense of progress towards the opening of the program served to keep morale high and to create the excitement necessary to recruit faculty and students.

Grounded in both educational and market research, CSU Engineering will exemplify a different paradigm for engineering education in Australia, and provide a distinct alternative to Australia's existing engineering degree programs.

\section{References}

1: Johnson, D.W., Johnson, R.T. \& Smith, K. (1991). Active Learning: Cooperation in the classroom. Edina, $\mathrm{MN}$ : Interaction Book.

2: International Engineering Alliance (2013) Graduate Attributes and Professional Competencies, Version 3. Sourced from http://www.ieagreements.org/IEA-Grad-Attr-Prof-Competencies.pdf 02-Feb-16

3: Lindsay, E D \& Morgan J R. (2015). Lessons Learned from Tangible Curriculum Week. Paper presented at the Australasian Association for Engineering Education Annual Conference, Torquay, VIC.

4: Australian Qualifications Framework Council (2013) Australian Qualifications Framework, $2^{\text {nd }}$ Edition. www.aqf.edu.au

5: Capraro, R.M., Capraro, M.M. \& Morgan, J.R. (Eds.) (2013). STEM Project-Based Learning: An Integrated Science, Technology, Engineering, and Mathematics (STEM) Approach, $2^{\text {nd }}$ Edition. Rotterdam: Sense Publishers.

6: Hake, R. R. (1988). Interactive-engagement vs. traditional methods: A six-thousand-student survey of mechanics test data fro introductory physics courses. American Journal of Physics, 66, 64-74.

7: Seat, E. \& Lord, S. (1999). Enabling effective engineering teams: A A program for teaching interaction skills. Journal of Engineering Education, 88, 385-390.

Acknowledgements

The authors gratefully acknowledge the contributions of many colleagues who have had both direct and indirect input into the development of the curriculum model described in this paper. 